\section{Maybe Next Year?}

\author{
Peter Black, Editor-in-Chief ${ }^{\bowtie}$
}

Soc Int Urol J.2021;2(3):137

DOI: 10.48083/AVBY2691

Remember just a few short months ago when we bid farewell to pandemic-ridden 2020 and ushered in 2021 with eager anticipation of returning to normal social activities, regular travel, and participation in-person in urologic meetings? While the vaccine effort plods along, more efficiently in some countries and regions than others (and certainly without any sense of global equity), you could well wonder if we will not at the end of this year find ourselves eagerly awaiting the same events for 2022. Coronamüde (corona-fatigued) rings loud for us all.

Which meeting will be the first big one in person? The American Urological Association (AUA) 2021 Annual Meeting is planned for late September in Las Vegas. The leadership of the AUA and the meeting organizers will certainly not take any public health risk in pulling off this meeting (they will not be swayed by their government's penchant for deviating from good public health policy throughout the pandemic), but travel restrictions and quarantine regulations have been looser in the United States than elsewhere, so it would be fitting if the AUA were the "homecoming" of sorts for the urologic community. COVID numbers continue to surge, however, with concern rising over even more contagious variants, and other major meetings planned during similar dates (eg, ESMO 2021) are sticking to the virtual format. Perhaps the AUA can pull off a successful meeting without cross-border travel, but many other organizations cannot, and it is not at all clear whether any of us will be traveling by September. Our own 41st Congress of the SIU looms large, scheduled for November 10 to 14 in Dubai, giving us two more months in the race to overcome social distancing.
That is not to say that the advent of virtual meetings does not have some real advantages. Which academic urologist flying around the world from speaking engagement to guideline panel to visiting professorship has not enjoyed a break from the hectic travel circuit? And instead of catering to those with the time and means to travel, many of our meetings have become more accessible to urologists and allied health care workers in all corners of the globe. This is particularly important to an organization like the SIU-but at the same time it is critically important that we interact in person with our colleagues from other regions to forge those relationships that bring us closer together and advance our field. The time and space for informal discussions is something that virtual meetings cannot provide. It is not just about meeting, but also about connecting.

The SIU introduced hybrid meetings with the launch of the SIU@U in 2015 before we even really talked about such a thing. Maybe this will be the way of the futurethe anticipation, engagement, and camaraderie of inperson meetings for those who can attend, matched with the easy access and convenience of virtual meetings for those who cannot.

Of course, thoughts of travel restrictions and bemoaning the lack of in person meetings ring hollow during a true global health crisis. This is not to diminish the human cost of the pandemic, which is enormous and should always be in the foreground. Nonetheless, these meetings are an important part of any society and indeed any medical specialty, and we are anxiously awaiting their return-whether it is in the fall of 2021 or maybe not until next year. 